\title{
Towards a Simulator for Green Smart Campus Systems
}

\author{
Priscila A. Moraes ${ }^{1}$, Flávia Pisani ${ }^{2}$, Juliana F. Borin ${ }^{1}$ \\ ${ }^{1}$ Universidade Estadual de Campinas, Campinas, Brazil \\ ${ }^{2}$ Pontifícia Universidade Católica do Rio de Janeiro, Rio de Janeiro, Brazil \\ \{priscila.moraes, juliana\}@ic.unicamp.br, fpisani@inf.puc-rio.br
}

\begin{abstract}
The 2030 Agenda for Sustainable Development aims to foster environmental protection, inclusive economic growth, and social inclusion. Universities are called to join this global effort and are expected not only to contribute with solutions for the sustainability challenges but also provide sustainable campi. Given this scenario, the main contributions of this paper are threefold: i) to illustrate how universities could contribute with the 2030 Agenda through smart campus solutions based on technologies such as Internet of Things, Big Data, and Cloud Computing; ii) to propose a framework to automatically collect data to generate and manage sustainability indicators in the university; and iii) to propose a simulator for green smart campus system which allows an adequate estimate of the required information and communication infrastructure.
\end{abstract}

\section{Introduction}

Sustainability is currently a very relevant topic. It is important to make today's population aware that any actions taken to preserve the planet now will directly affect the quality of life of future generations.

In 2015, the United Nations (UN) met with representatives from several countries around the world [Nations 2019] and together they defined the 17 "Sustainable Development Goals (SDGs)" [Goals 2019]. These goals are aimed at sustaining the three pillars [Wu et al. 2018] (economic, social, and environmental) that are encompassed by sustainability. Figure 1 shows the names of the 17 goals to be achieved by 2030. Each of these goals has a set of targets, with an overall total of 169 targets and 232 indicators.

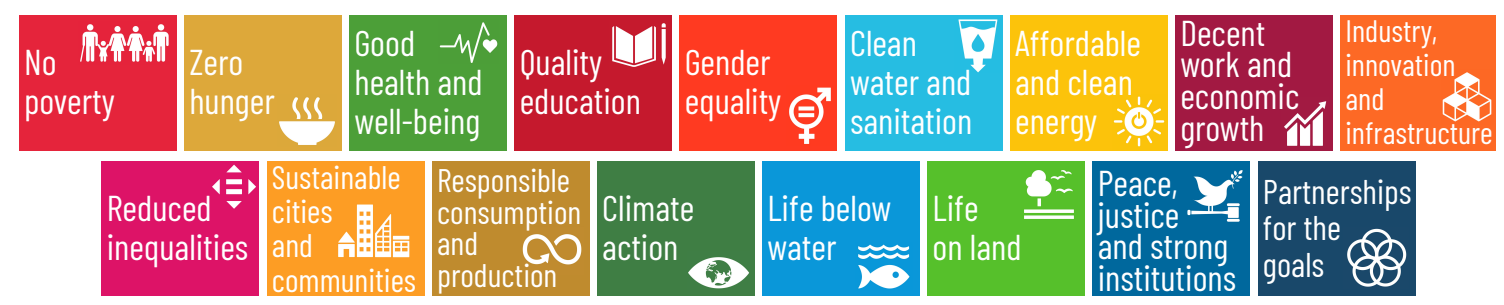

Figure 1. United Nations' Sustainable Development Goals.

In this context, even though a university's main goals are connected to research and education, it can also be an ideal setting for carrying out actions that will contribute to the environment and to sustainability in general. First, the university is an opinion maker, and thus plays an important role in raising people's awareness of the importance of the topic to society as a whole. Furthermore, there is also the possibility of developing 
research and solutions that can directly assist sustainable development and improve the quality of life of the community.

Therefore, universities must pay attention to how they can contribute directly or indirectly to achieving UN goals. One way they can work towards this internally is by implementing green smart campus solutions. A smart campus is one where physical and virtual spaces interact through the use of intelligent devices [Petcovici and Stroulia 2016], generating relevant data that, when processed, produce knowledge to support the management and the integration of work, study, and living environments [Enqing et al. 2017]. For instance, by implementing green smart campus solutions, a university can monitor the use of its resources (e.g., water and energy) and automatically reduce their consumption.

To provide smart campus solutions that can help achieve the SDGs, it is necessary to build an entire network of IoT devices capable of communicating with a centralized system. The devices should be installed in strategic locations where they can collect data for sustainability metrics. For example, in classrooms or auditoriums, the measurements can be related to electrical energy consumption, with sensors placed in lamps, air conditioners, and power outlets. We can also measure energy consumption in bathrooms, as well as the water consumption of faucets, toilets, and showers. In restaurants, we can measure water and energy consumption, while also placing smart meters in garbage cans to quantify how much food is wasted and how much is used for composting.

Considering the whole university, we expect that the number of IoT devices that must be installed and the amount of data they will generate will be very large. Therefore, several challenges and questions arise, such as: 1) "How much data will all these devices combined generate;" 2) "How much data will go through a certain point of the network in an instant of time;" 3) "Will this data traffic cause Internet access to be slow for the people on campus;" 4) "Will it be necessary to create a dedicated network for the IoT devices, regardless of which network provides Internet access;" 5) "How much storage space should be reserved for these data; 6) "Should the storage be local or in the cloud."

Before installing the measuring devices, it is important to assess all infrastructure requirements and calculate the budget for the project implementation. In this context, our work aims at meeting this demand by providing a simulator that considers not only the university environments and their elements (e.g., rooms, bathrooms, streets, utility poles, gates, etc.), but also the IoT devices to be installed in each environment. By modeling a green smart campus system inside the simulator, we intend to characterize the amount of data generated and how much traffic will exist at each network point.

In this paper, we present our ongoing efforts towards the creation of this simulator for green smart campus systems. The simulated system will integrate various existing smart campus solutions and will be capable of automatically collecting, through sensors and IoT devices, relevant data for the calculation of sustainability metrics. The simulator will report the amount of traffic and storage used by the system based on information such as the data collection rates and the geographical location of devices, thus allowing administrators to determine all the necessary infrastructure requirements before actually implementing the system in the real world. 


\section{Related Work}

Several technologies have been used to create smart campus solutions. Among them, the following stand out: Big Data [Hu and Yan 2016, Wei 2016, Yan and Hu 2016]; cloud computing [Guo and Zhang 2015, Zhang and Jiang 2018]; Internet of Things (IoT) [Arshad et al. 2017, Guo and Zhang 2015, Ivanovski 2015, Majeed and Ali 2018]; Internet and high performance computing [Nie 2013]; virtualization, mobile Internet, and social networks [Hu and Yan 2016]; sensors and common communication interfaces [Nati et al. 2017]; 6LoWPAN (IPv6 over Low Power Wireless Personal Area Networks) [Luo 2018]; and RFID (Radio-Frequency Identification) [Kwok 2015].

Moreover, many of the solutions developed to achieve smart campus goals also have the potential to promote the development of sustainable goals inside of universities. This work only focuses on SDGs that can both be measured by IoT devices and be directly achieved by a university campus, such as the ones related to the environment. Table 1 maps a set of recent smart campus solutions which use the technologies previously mentioned to five such SDGs.

Table 1. Correlation between smart campus solutions and SDGs.

\begin{tabular}{||l|l|l||}
\hline \hline$\#$ & Description & Smart campus solution \\
\hline \hline 6 & Clean water and sanitation & [Kuo et al. 2018] \\
\hline 7 & $\begin{array}{l}\text { Affordable and clean } \\
\text { energy }\end{array}$ & $\begin{array}{l}\text { [Wang et al. 2017], [John et al. 2017], } \\
\text { [Okeniyi et al. 2018], [Akindeji et al. 2019], } \\
\text { [Cypriano et al. 2019], [Weng et al. 2019], } \\
\text { [Yuliansyah et al. 2019] }\end{array}$ \\
\hline 11 & $\begin{array}{l}\text { Sustainable cities and } \\
\text { communities }\end{array}$ & [Li et al. 2017b], [Subbarao et al. 2019] \\
\hline 12 & $\begin{array}{l}\text { Responsible consumption } \\
\text { and production }\end{array}$ & [Lo 2019] \\
\hline 13 & Climate action & $\begin{array}{l}\text { [Adenle and Alshuwaikhat 2017], [Li et al. 2017a], } \\
\text { [Rodrigues et al. 2019] }\end{array}$ \\
\hline \hline
\end{tabular}

Given the amount of smart campus solutions that can be related to the SDGs, we see that the university is an environment conducive to the achievement of these UN goals. Throughout our work, we intend to combine several of these existing solutions to create a unified green smart campus framework (SDGreen), as is further detailed in Section 3.

It is important to note, however, that the information and communication infrastructure in most universities is not prepared to handle the great amount of data that will be generated by applications monitoring all of its spaces. One of the strategies widely used to estimate computational infrastructure demand is simulating the expected scenario. This work proposes SDGreenSim, a simulator of the SDGreen framework. To the best of our knowledge, there is no work focusing on the simulation of the whole computational infrastructure of green smart campus systems. Such a simulator could greatly contribute to the decision making process at universities when administrators are preparing the infrastructure to support the new applications.

SenSE [Zyrianoff et al. 2017] (1) generates synthetic data simulating a sensor net- 
work. The user can choose the types and the number of sensors and each type of sensor has a fixed time interval in which it sends the data. For instance, the air quality and noise sensors send messages every 30 minutes to the central server, while the people flow sensor sends a message when a person is detected by the device. The system is implemented using threads and parallel computing, with a queue to represent the arrival of events. SenSE provides a web interface and is open source.

GlobeTraff [Katsaros et al. 2012] (2) generates traffic based on four models: Web, Video, P2P, and Other traffic. The distributions are based on mathematical models such as Zipf-like, Weibull, and Gamma distribution with parameters configured by the user. In addition, it is necessary to configure the percentage of traffic of each application.

UbikSim [Campuzano et al. 2014] (3) simulates the behavior of people in the university. The human behavior is modeled based on the collection of data through questionnaires about the schedule of each person on campus. After that, the system builds the timeline based on the existing registered data, such as university locations. The result is a flow chart representing a typical student week.

Al Rawajbeh [Al Rawajbeh 2018] (4) simulates smart campus applications based on the IoT and focuses his analysis on human-computer interaction issues. He modeled several types of elements including sensors, actuators, hubs, and others smart devices.

IntersCSimulator [Santana et al. 2017] (5) is a smart city simulator. It simulates the movement of cars and people in different routes, as well as bus and subway systems. The output of the simulator provides easy-to-read statistics.

CupCarbon [Mehdi et al. 2014] (6) is a multi-agent sensor and geolocation-based discrete event simulator. It simulates sensors and other elements such as moving objects, mobile or static natural events (gas, temperature, humidity, etc.), and sunlight for solar panel implementation calculations. It has a friendly interface using the OpenStreetMap (OSM) framework, placing the sensors directly on the map. The simulator is able to represent in detail the energy diagram associated with time. It has its own scripting language, called SenScript, to implement power and sensor behavior.

Table 2 compares the aforementioned simulators using the following criteria: A) Automatic data generation, which means that the simulator can generate data traffic, otherwise, it requires the input of a dataset. B) Data collecting devices, which indicates the types of devices supported by the simulator. They can be only sensors (OS) or multiagents (MA), meaning sensors or other data capture devices (e.g., cameras). C) Smart Campus, which indicates whether or not the simulator focuses on smart campus scenarios. D) SDG indicators, which means that the simulated data can be used to calculate indicators for the SDGs. E) Requires specialized user, which means that users should have a certain level of knowledge about computing or mathematics to use the simulator, for instance, XML format or mathematical models (Zipf-like, Weibull and Gamma distribution). F) Open source, which indicates whether or not the simulator is available as open-source software. G) Amount of network traffic, which indicates that the simulator provides ways to measure the amount of network traffic generated by the simulated data. 
Table 2. Simulator comparison. $M A=$ Multi-agents and OS = Only sensors.

\begin{tabular}{||c|l|c|c|c|c|c|c|c||}
\hline \hline & Characteristic & SDGreenSim & $(1)$ & $(2)$ & $(3)$ & $(4)$ & $(5)$ & $(6)$ \\
\hline \hline A & Automatic data generation & Yes & Yes & Yes & No & Yes & Yes & Yes \\
\hline B & Data collecting devices & MA & OS & MA & - & MA & MA & MA \\
\hline C & Smart Campus & Yes & No & No & Yes & Yes & No & No \\
\hline D & SDG indicators & Yes & Yes & No & No & Yes & Yes & Yes \\
\hline E & Requires specialized user & No & No & Yes & No & No & Yes & Yes \\
\hline F & Open source & Yes & Yes & No & No & No & Yes & No \\
\hline G & Amount of network traffic & Yes & Yes & Yes & No & No & No & No \\
\hline \hline
\end{tabular}

\section{Proposal}

This section describes our proposal for: 1) a framework that will allow collecting and processing sustainability data; and 2) a system simulator that will allow data traffic and storage space calculations based on the system's infrastructure characteristics.

\subsection{SDGreen - Green Smart Campus Framework}

There are 17 SDGs and 169 targets to be achieved by 2030. It is possible to handle the majority of them by enabling proactive actions through the use of automated data collection. Thus, there is a need for the implementation of a framework that enables sustainabilityrelated information to be collected without human intervention and then processed to create sustainability indicators. Figure 2 depicts our proposal for this framework.

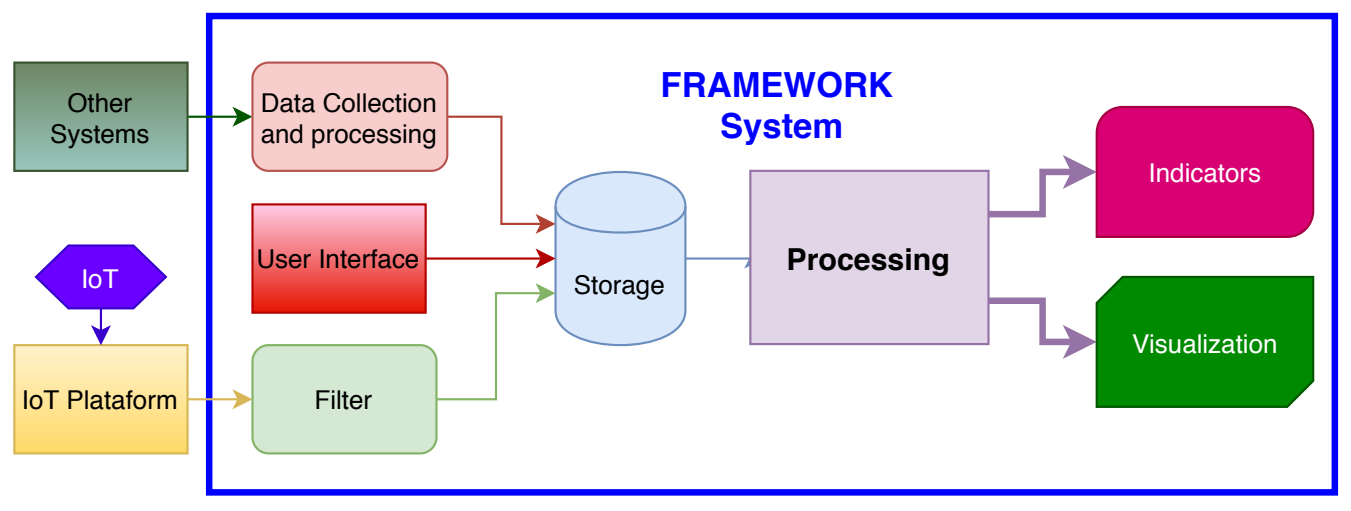

Figure 2. SDGreen - Framework for collecting and processing sustainability data.

Other systems: the framework must be able to request data from external systems to help characterize the university environment. Examples of systems from which this information can be extracted are systems that take care of the university's human resources and geo-processing systems (e.g., the Geographic Information System GIS [Li and Guan 2011, Enqing et al. 2017, Company 2019]).

User interface: the system must also provide a way for data to be inserted manually (e.g., for testing and debugging purposes).

IoT devices: the goal is that most of the measurements will come from IoT devices. In addition to useful data, these devices can collect information that is not relevant to the calculation of the sustainability indicator, so it may be necessary to filter it before it is stored and used. 
In addition to calculating sustainability indicators, the data processed by the framework can also lead to actuation. For instance, it is possible to dim the lights or reduce the intensity of the air conditioning in a building where high energy consumption is detected, thereby contributing to achieving the 7.1 target (ensure universal access to affordable, reliable, and modern energy services) of SDG7.

\subsection{Green Smart Campus System Simulator}

We can expect that the large volume of data generated by a green smart campus system may not be supported by the existing university infrastructure. This way, it is desirable that administrators be able to adequately estimate the system requirements even before it is physically implemented. To help with this task, we propose the development of a simulator for a campus environment instrumented with sensors and IoT devices. Each device will be configured to simulate measurements that will be used by the framework to generate sustainability indicators. In this scenario, the main challenges will be related to the volume and velocity of the collected data. Therefore, the simulator will calculate the resources needed to install the system, such as bandwidth and network technology and size and type of storage space.

To illustrate the characterization of such a scenario, Figure 3 presents a map of a university campus, highlighting the locations where IoT devices and sensors could be installed to contribute to the achievement of the SDGs and their targets (targets are indicated by a dot after the SDG number).

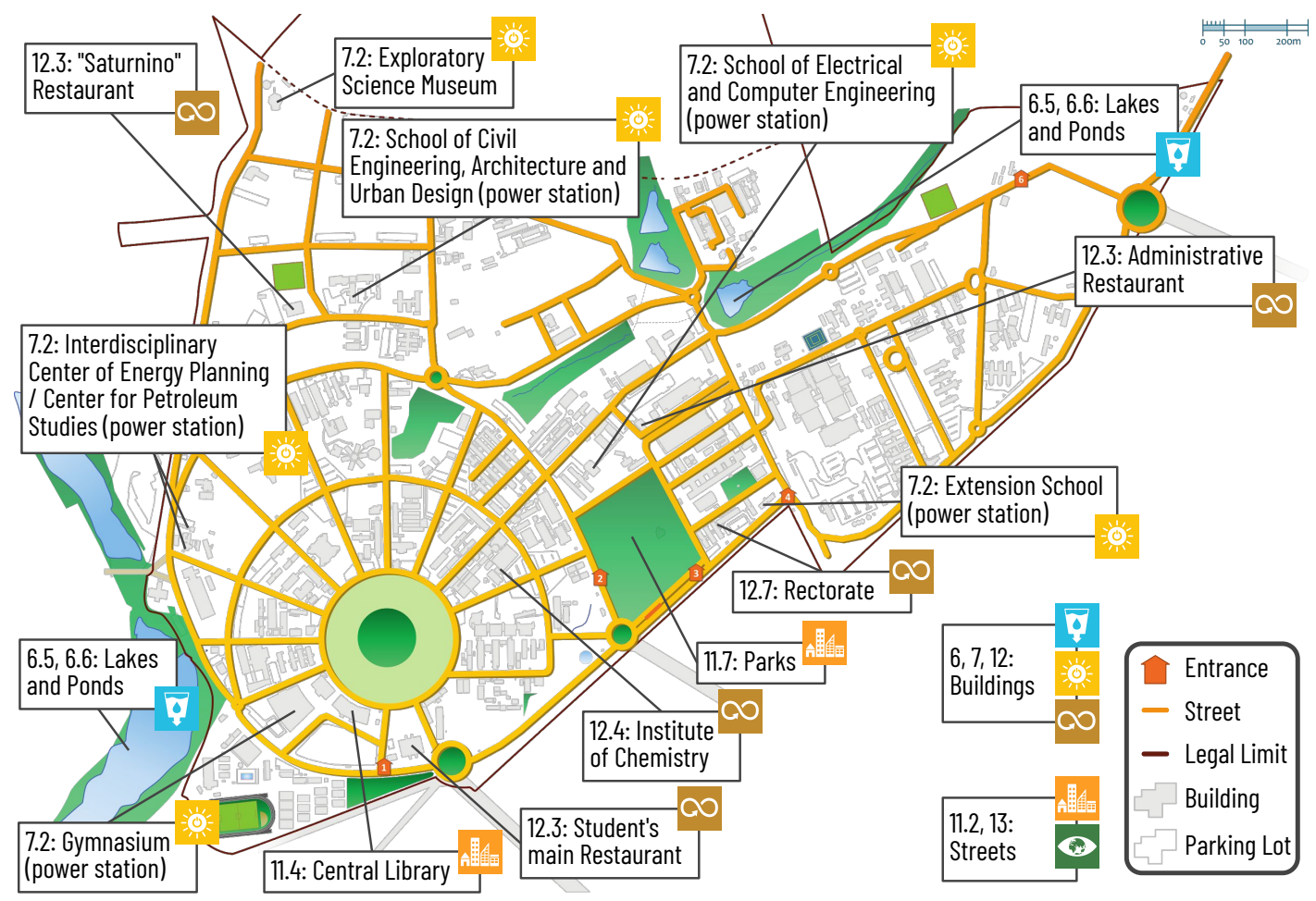

Figure 3. UNICAMP Campinas campus map and SDGs [UNICAMP 2020].

The university as a whole can help with target 12.8 , which aims to ensure that people have relevant information and awareness about sustainable development. In all 
university buildings, meters can be placed to help generate indicators for SDGs 6 (drinking water and sanitation - targets 6.1, 6.2, 6.3, and 6.4, which are related to drinking water, sanitation and hygiene, water quality, and water-use efficiency, respectively), 7 (affordable and clean energy), and 12 (sustainable communities - targets 12.2 and 12.5, which are related to management and use of natural resources and waste reduction, respectively). The streets of the campus, through the generation of less carbon by means of public transportation, can contribute to the improvement of SDG 13 (action against global climate change) and target 11.2 (safe, accessible, sustainable transportation systems). At the university where this work is being carried out (University of Campinas - UNICAMP) there is also a photovoltaic plant that meets target 7.2 (renewable energy). Furthermore, we have that parks can contribute to target 11.7 (safe and green public space), libraries to 11.4 (cultural heritage), restaurants to 12.3 (halving food waste), the Institute of Chemistry to 12.4 (environmentally adequate management of chemicals), and the rectorate to 12.7 (promoting sustainable public purchasing practices).

The simulator will receive the information about the campus environments and their respective devices from the user, allowing them to either manually provide this information or load it from a geo-referencing system such as GIS. The environment modeled by the simulator can be as generic or as specialized as the user wishes. In our instance of the simulator, we will perform a characterization of all environments of the university depicted in Figure 3, including all the elements that are considered important for sustainability within the campus. We will also characterize the places where IoT devices and access points may be installed to provide the necessary infrastructure for the calculation of sustainability indicators. This characterization will include details such as the types of devices, the types of data they collect, and their geo-location.

We will start by making this characterization on a conceptual level, modeling the university in terms of its generic elements, such as people, rooms, libraries, vehicles, trees, streets, among others. After this theoretical characterization, we will implement it in software. All the characterized environments will be modeled as classes where each object will represent a real world element. Once the user has defined the system they want to simulate, they will be able to add or remove elements from the simulator so that it exactly represents the environment in terms of devices to be installed on site. For the objects that represent devices, there will be attributes representing the interval between the measurements and the data type collected, thus allowing the software to calculate the total data size and network traffic.

After the construction of this virtual campus environment, the user will be able to run the simulation. The simulated system will generate data at the specified rate and send it through the network of each of the mapped environments. By observing the velocity of the simulated data, it will be possible to map the type of technology to be used at each data traffic point, as well as the necessary bandwidth to be made available on site. By analyzing the volume of the data that will be generated with the specified configuration, it will also be possible to calculate the size of storage space required. These reports can then be used by administrators to calculate resources needed to implement the system as a whole. Moreover, if the necessary budget to implement the infrastructure is beyond what the university has allocated for this purpose, it is possible to change the interval between measurements and run the simulation again to recalculate the requirements. 


\section{Conclusion}

The 17 SDGs are a call for action for all society. In this way, universities are expected to not only to propose solutions for the sustainability challenges, but also to implement them in their campi. Solutions based on IoT and data analysis have been proposed to leverage smart campus scenarios and, as discussed in this paper, many of them have the potential to contribute to the achievement of SDGs targets. Nevertheless, universities still lack a systematic and automated approach to measure and manage their sustainability indicators. This work in progress proposes a framework to automatically collect data generated through smart campus technologies as well as from other legacy systems in the university aiming to support sustainability management. Monitoring all the university spaces can result in a large amount of network traffic and data to be stored, so the work also proposes the development of a simulator to allow a more precise planning of the physical infrastructure needed to implement such framework. We intend to continue this investigation by implementing the proposed framework and simulator and testing it on a real-world use case at the University of Campinas (UNICAMP).

\section{Acknowledgments}

The authors thank FAPESP (grant \#2019/19312-9), CNPq (grant \# 155042/2016-5), and CAPES for the financial support.

\section{References}

Adenle, Y. A. and Alshuwaikhat, H. M. (2017). Spatial estimation and visualization of co2 emissions for campus sustainability: The case of king abdullah university of science and technology (kaust), saudi arabia. Sustainability, 9(11).

Akindeji, K. T., Tiako, R., and Davidson, I. E. (2019). Use of renewable energy sources in university campus microgrid - a review. In Proc. DUE, pages 76-83.

Al Rawajbeh, M. (2018). A new framework simulation for developing and designing a smart campus application. IJFCC, 7:58-62.

Arshad, S., Azam, M. A., Ahmed, S. H., and Loo, J. (2017). Towards information-centric networking (icn) naming for internet of things (iot): The case of smart campus. In Proc. ICFNDS, pages 41:1-41:6.

Campuzano, F., Doumanis, I., Smith, S., and Botia, J. A. (2014). Intelligent environments simulations, towards a smart campus. In 2nd International Workshop on Smart University.

Company, E. (2019). Arqgis online. [Accessed Nov. 12, 2019].

Cypriano, J. G. I., Pinto, L. F., Machado, L. C., da Silva, L. C. P., and Ferreira, L. S. (2019). Energy management methodology for energy sustainable actions in university of campinas - brazil. IOP Conf. Ser. Earth Environ. Sci., 257:012034.

Enqing, J., Peixiang, R., Huanjin, W., and Yanping, S. (2017). Discussion on construction method of smart campus basic platform based on $3 \mathrm{~d}$ geographic information technology. In Proc. CAC, pages 7790-7794.

Goals, T. G. (2019). The global goals for sustainable development. [Accessed Mar. 15, 2019]. 
Gomes, R., Pombeiro, H., Silva, C., Carreira, P., Carvalho, M., Almeida, G., Domingues, P., and Ferrão, P. (2017). Handbook of Theory and Practice of Sustainable Development in Higher Education : Volume 1, chapter Towards a Smart Campus: BuildingUser Learning Interaction for Energy Efficiency, pages 381-398. Springer International Publishing, Cham.

Guo, M. and Zhang, Y. (2015). The research of smart campus based on internet of things amp;amp; cloud computing. In Proc. 11th WiCOM, pages 1-6.

Hu, H. and Yan, H. (2016). A study on discovery method of hot topics based on smart campus big data platform. In Proc. ICITBS, pages 176-179.

Ivanovski, D. (2015). The "green" in internet of things: Case study of faculty environment. In Uden, L., Heričko, M., and Ting, I.-H., editors, Proc. KMO, pages 561-571.

John, T. M., Ucheaga, E. G., Badejo, J. A., and Atayero, A. A. (2017). A framework for a smart campus: A case of covenant university. In Proc. CSCI, pages 1371-1376.

Katsaros, K. V., Xylomenos, G., and Polyzos, G. C. (2012). Globetraff: A traffic workload generator for the performance evaluation of future internet architectures. In 5th NTMS, pages $1-5$.

Kuo, W., Pan, C., and Lin, L. (2018). Wastewater treatment and reuse on campus: A case study in kun shan university. In Proc. 4th GTSD, pages 583-586.

Kwok, L.-f. (2015). A vision for the development of i-campus. Smart Learn. Environ., $2(1): 2$.

Li, L., Huang, H., Zhao, F., Sutherland, J. W., and Liu, Z. (2017a). An energy-saving method by balancing the load of operations for hydraulic press. IEEE/ASME T. Mech., 22(6):2673-2683.

Li, R. and Guan, Q. (2011). Environmental campus: Managing campus parking meters using gps and gis. In Proc. ISWREP, volume 4, pages 3180-3182.

Li, Y., Chen, H., Shao, W., Jing, S., Chiu, F., and Su, H. J. (2017b). Practices of innovative technology and education for sustainability in taiwan sustainable campus program. In Proc. PNC, pages 15-22.

Lo, Y.-Y. (2019). Creating a sustainable campus through digitalization : Exploring workplace practices to increase employee engagement. Master's thesis, KTH, School of Electrical Engineering and Computer Science (EECS).

Luo, L. (2018). Data acquisition and analysis of smart campus based on wireless sensor. Wireless Pers. Commun., 102(4):2897-2911.

Majeed, A. and Ali, M. (2018). How internet-of-things (iot) making the university campuses smart? qa higher education (qahe) perspective. In Proc. 8th CCWC, pages 646-648.

Malatji, E. M. and Ntsaluba, S. B. K. (2018). Smart energy generation for a smart campus. In Proc. ICONIC, pages 1-5.

Mehdi, K., Lounis, M., Bounceur, A., and Kechadi, T. (2014). Cupcarbon: A multi-agent and discrete event wireless sensor network design and simulation tool. In 7 th ICST, pages $126-131$. 
Nati, M., Gluhak, A., Domaszewicz, J., Lalis, S., and Moessner, K. (2017). Lessons from smartcampus: External experimenting with user-centric internet-of-things testbed. Wireless Pers. Commun., 93(3):709-723.

Nations, U. U. (2019). Sustainable development goals. [Accessed Nov. 12, 2019].

Nie, X. (2013). Constructing smart campus based on the cloud computing platform and the internet of things. In Proc. 2nd ICCSEE, pages $1576-1578$.

Okeniyi, J. O., Atayero, A. A., Popoola, S. I., Okeniyi, E. T., and Alalade, G. M. (2018). Smart campus: Data on energy generation costs from distributed generation systems of electrical energy in a nigerian university. Data Brief, 17:1082 - 1090.

Petcovici, A. and Stroulia, E. (2016). Location-based services on a smart campus: A system and a study. In Proc. 3rd IEEE WF-IoT, pages 94-99.

Rodrigues, P. L., dos Santos Rabello, R., and Cervi, C. R. (2019). An application to generate air quality recommendations and alerts on a smart campus. In Stephanidis, C., editor, HCI International 2019 - Posters, pages 507-514.

Santana, E. F. Z., Lago, N., Kon, F., and Milojicic, D. S. (2017). Interscsimulator: Largescale traffic simulation in smart cities using erlang. In 18th MABS, pages 211-227. Springer.

Subbarao, V., Srinivas, K., and Pavithr, R. S. (2019). A survey on internet of things based smart, digital green and intelligent campus. In Proc. 4th IoT-SIU, pages 1-6.

UNICAMP (2020). Unicamp Campinas campus map. [Accessed Mar. 13, 2020].

Wang, Y., Saez, B., Szczechowicz, J., Ruisi, J., Kraft, T., Toscano, S., Vacco, Z., and Nicolas, K. (2017). A smart campus internet of things framework. In Proc. 8th IEEE UEMCON, pages 498-503.

Wei, L. (2016). Campus management strategy research under the environment of big data. In Proc. ICITBS, pages 195-199.

Weng, Y., Zhang, N., and Xia, C. (2019). Multi-agent-based unsupervised detection of energy consumption anomalies on smart campus. IEEE Access, 7:2169-2178.

Wu, J., Guo, S., Huang, H., Liu, W., and Xiang, Y. (2018). Information and communications technologies for sustainable development goals: State-of-the-art, needs and perspectives. IEEE Commun. Surv. Tut., 20(3):2389-2406.

Yan, H. and Hu, H. (2016). A study on association algorithm of smart campus mining platform based on big data. In Proc. ICITBS, pages 172-175.

Yuliansyah, H., Corio, D., Yunmar, R. A., and Aziz, M. R. K. (2019). Energy monitoring system based on internet of things toward smart campus in institut teknologi sumatera. IOP Conference Series: Earth and Environmental Science, 258:012008.

Zhang, W. and Jiang, L. (2018). Algorithm analysis for big data in education based on depth learning. Wireless Pers. Commun., 102(4):3111-3119.

Zyrianoff, I., Borelli, F., and Kamienski, C. (2017). Sense - sensor simulation environment: Uma ferramenta para geração de tráfego iot em larga escala. Salão de Ferramentas - SBRC. [In Portuguese]. 